\title{
Seeds of thought for plant conservationists
}

\section{from Peter D. Moore}

A RECENT paper' describing the successful germination during greenhouse tests of the fen violet, Viola persicifolia, in soil samples taken from Wicken Fen, Cambridge, where the violet had been believed to have been extinct since 1916 , raises two important questions. First, for how long can seeds remain viable? And second, how should conservationists define extinction for a plant species at a site?

Some answers to the first question come from discoveries of plant seeds in datable archaeological contexts. The Canna necklace, found during the excavation of a tomb in Argentina, comprised a string of rattles made of walnut shells (Juglans australis) containing Canna seeds ${ }^{2}$. When kept moist and dark the Canna seeds germinated. Bone material from the same site was radiocarbon-dated at 530 years old. Godwin ${ }^{3}$, however, questioned the association between the bone (of a camelloid animal) and the necklace, and hence cast doubt upon the validity of this claim for an ancient viable seed. Godwin's doubts stimulated Lerman and Cigliano ${ }^{4}$ to redate the material, this time using the Juglans nutshell. They obtained a date of $620 \pm 60$ years ago, thus confirming the antiquity of the viable seed.

Only too of ten, however, the association between artefact and seed is rather tenuous and hence the dating of the seed unreliable. Such is the case with the 3,000-year-old canoe found near Tokyo with 'associated' viable water lily seeds. These could easily have been derived from later contaminant sediments ${ }^{2}$.

Experimental work on seed viability must, by its very nature, be long term and few have had the patience or foresight to set up seed-viability experiments. There was the Kentish schoolboy, Peter Ashenden, who entombed a bottle of wheat grains in a new wall built around his school in $\mathbf{1 8 7 2}$. This time-capsule eventually came to light a century later, during demolition works, but when the seeds were tested at the ARC Unit in Developmental Botany, Cambridge, they were found to be non-viable ${ }^{6}$.

Just eight years after Peter Ashenden had begun his experiment in England, Professor W.J. Beal began a more ambitious and well documented experiment in Michigan, USA. Twenty samples of selected seeds were mixed with moist sand, placed in uncorked bottles and buried, neck downwards (to avoid waterlogging), in a field. For the first 35 years one sample was removed and tested every 5 years, but subsequently the interval has been increased to 10 years. The latest sample to be removed (the fourteenth bottle) was recovered in
1980 , a century after burial, and a total of 27 of the original 1,000 seeds (mainly $\mathrm{Ver}$ bascum blattaria) germinated ${ }^{7}$. The experiment could be criticized, however, on the grounds that open-necked bottles could permit access by earthworms and other soil arthropods which carry seeds in their gut ${ }^{8}$.

The sealing of seeds in walls has been going on, albeit inadvertently, for some considerable time in areas far removed from Kent. In California and Northern Mexico, for example, the adobe bricks of buildings contain the seeds from the mud of which they were built. In a recent study, Spira and Wagner ${ }^{9}$ examined extracted seeds from the bricks of 20 adobe buildings constructed between 1769 and 1837 . Most of the seed samples had been recovered by archaeologists working 50 years ago and had been stored dry since then in glass vials at room temperature. Of about 40 species tested, 7 were found to have at least one viable seed (tested chemically) and 1 species, Medicago polymorpha, was successfully germinated to produce a seedling. It is open to question whether the viability would have been greater if samples had been taken directly from the adobe bricks instead of from storage tubes.

The possibility of long-term survival of seeds buried in soils or compacted in mud brings us to the question of defining extinction of a plant species at a site. The loss of the vegetative stage in a plant's life history, even if its absence continues for several decades, does not necessarily prove that the species does not survive as dormant seed.

The importance of this possibility was realized when a plant species supposedly extinct in Britain, the fen ragwort (Senecio paludosus), was re-discovered in East Anglia in 1972 after an apparent absence of about 70 years $^{10}$. Survival of buried seeds seemed a more likely cause of its re-appearance than re-invasion from elsewhere. In the more recent case of Viola persicifolia, almost certainly the seed had survived dormant in the soil since the early part of this century. In such a situation the next question which must be faced is how one can best manage the site in order to provide suitable conditions for the dormant species to emerge from its latent state.

Perhaps the time is approaching when nature reserves will be established not simply on the basis of their current vegetation, but as a result of the potential interest of their soil seed banks.

Peter D. Moore is a Lecturer in the Department of Plant Sciences, University of London King's College, 68 Half Moon Lane, London SE24 9JF.

\footnotetext{
Rowcll, T.A., H'alters, S.M. \& Harvey, H.J. Watsonia 14 183 (1982).

2. Sivori, E., Nakayanı, F. \& Cigliano, E. Nature 219. 1269 (1968).

Godwin, H. Nature, 220, 708 (1968)

4. I.crman, J.C. \& Cigliano, E.M. Nature 282, 568 (1971).

5. Godwin. H. \& W'ills, E.H. New Phytol. 63, 410 (1964).

6. Osborne, D. New Scient. 63, 252 (1974).

. Kivilaan, A. \& Bandurski, R.S. Am. J. Bot. 68, 1290 (1981)

McRill, M. \& Sagar, Gi.R. Nature 243, 482 (1973).

9. Spira. T.P. \& Wagner, L.K. Am. J. Bot. 70,303 (1983)

10. Spira. T.P. \& Wagner, I.K. Am. J. Bor.
}

\section{Meteorites}

\section{Calcium- and aluminium-rich inclusions}

\section{from Derek W.G. Sears}

IN recent months there have been new developments in our understanding of calcium-aluminium-rich inclusions (CAI) and the meteorites in which they are found. Meeker, Wasserburg and Armstrong ${ }^{1}$ argue that some CAI have suffered considerable alteration by processes which occur on small parent bodies. This adds a new episode to the history of the objects and their parent meteorites. And in this issue of Nature (p.588), Bischoff and $\mathrm{Keil}^{2}$ discuss several CAI they have found in the largest meteorite class, the ordinary chondrites. Although there are many earlier studies of occasional CAI (see, for example, ref.3), it is the fact that Bischoff and Keil found CAI in every one of the 11 ordinary chondrites they examined which is significant.

CAI are light-coloured inclusions varying in size from millimetres to centimetres ${ }^{4,5}$, and which were first found in quantity in the Allende meteorite. The in- clusions were found to have had extremely low initial ${ }^{87} \mathrm{Sr} /{ }^{86} \mathrm{Sr}$ ratios, indicating that they were one of the earliest substances to form in the Solar System ${ }^{6}$. They were also found to be rich in all the refractory elements ${ }^{7}$ and to consist of a number of calcium- and aluminium-rich minerals which had previously been considered either absent or rare in meteorites. In 1973 they were found to have anomalous oxygen isotope abundances ${ }^{8}$ and soon a whole plethora of isotopic anomalies were reported; elements such as $\mathrm{Ca}, \mathrm{Ti}, \mathrm{Sr}, \mathrm{Ba}$, $\mathrm{Sm}$ and $\mathrm{Nd}$ were all found to have relative isotopic abundances that were not explicable in terms of well-defined chemical processes or nuclear processes such as radioactive decay or cosmic-ray-induced nuclear reactions ${ }^{9}$. Moreover, excess ${ }^{26} \mathrm{Mg}$ and ${ }^{129} \mathrm{Xe}$, the products of radioactive decay of ${ }^{26} \mathrm{Al}\left(t_{1 / 2}=0.75 \mathrm{Myr}\right)$ and ${ }^{129} \mathrm{I}$ $\left(t_{1 / 2}=18 \mathrm{Myr}\right)$ respectively, were 